\title{
Atomic mechanisms of high-speed migration of symmetric tilt grain boundaries in nanocrystalline $\mathrm{Ni}$
}

\author{
K. P. Zolnikov ${ }^{\dagger}$ D. S. Kryzhevich, A. V. Korchuganov \\ †kost@ispms.ru
}

Institute of strength physics and materials science SB RAS, 2/4 Alademicheskii Av., Tomsk, 634055, Russia

Molecular dynamics simulations of structural rearrangements in nanocrystalline $\mathrm{Ni}$ with the symmetric tilt grain boundary (GB) $\sum 5$ (310) [001] under shear loading were conducted. It was found that GB can be displaced in the direction perpendicular to the shear loading direction. To activate the displacement, it is necessary to reach the threshold value of the shear stress. The GB displacement is abrupt and is due to a certain sequence of displacements of the atomic planes adjacent to the GB. These planes are successively rebuilt from the structure of one grain to the structure of another grain in the process of GB migration. The velocity of GB migration can reach several hundred meters per second and depends on the rate of shear loading. The use of periodic boundary conditions prevents the rotations of the grains. As the simulated tilt GB is symmetric, both of the crystallite grains will have the same shear moduli in the direction of the applied loading. The shear loading of the crystallite with such a structure does not lead to any volume driving forces. The GB displacement was entirely due to the coupling effect. The shear stress curve as a function of time has a sawtooth shape. The GB experiences displacement upon reaching the maximum value of the applied shear stresses. Despite the high stress values, the GB displacement did not cause the nucleation of the defect structure in the crystallite. The GB migration is accompanied by a change in the volume of atoms involved in structural rearrangements.

Keywords: nanocrystalline materials, grain boundary migration, shear loading, atomic displacements, molecular dynamics.

УДК: 548.4:620.186.8

\section{Атомные механизмы высокоскоростной миграции симметричных наклонных границ зерен \\ в нанокристалле никеля}

\author{
Зольников К. П. ${ }^{\dagger}$, Крыжевич Д. С., Корчуганов А. В. \\ Институт физики прочности и материаловедения СО РАН, пр. Академический, 2/4, Томск, 634055, Россия
}

Проведено молекулярно-динамическое моделирование структурных перестроек в кристаллитах никеля с наклонной симметричной границей зерен (Г3) $\Sigma 5$ (310) [001] при сдвиговом нагружении. Обнаружено, что Г3 может смещаться в боковом и перпендикулярном направлении к направлению сдвига. Для активации смещения необходимо достижение порогового значения напряжения сдвига. Смещение ГЗ носит скачкообразный характер и обусловлено последовательностью из трех характерных смещений атомных плоскостей, прилегающих к ГЗ. В процессе миграции ГЗ эти плоскости последовательно перестраиваются из структуры одного зерна в структуру другого зерна. Скорость смещения ГЗ может составлять несколько сотен метров в секунду и зависит от скорости сдвигового нагружения. Использование периодических граничных условий предотвращало повороты зерен. Поскольку моделировались симметричные наклонные ГЗ, то оба зерна кристаллита имели одинаковые модули сдвига в направлении приложенного нагружения. Сдвиговое нагружение кристаллита с такой структурой не приводило к возникновению каких-либо движущих сил в объеме материала. Смещение ГЗ было полностью обусловлено эффектом взаимосвязи. Кривая зависимости сдвигового напряжения от времени имела пилообразную форму. ГЗ испытывала смещение в боковом и нормальном направлении к ее плоскости, когда приложенная сдвиговая нагрузка достигала максимального значения и начинала скачкообразно уменьшаться. Несмотря на высокие значения напряжений, смещение ГЗ не вызывало зарождение дефектной структуры в моделируемом кристаллите. Миграция ГЗ обеспечивалась скачкообразными изменениями атомных объемов в плоскостях, которые трансформировались из структуры одного зерна в структуру другого.

Ключевые слова: нанокристаллические материалы, миграция границ зерен, сдвиговое нагружение, атомные смещения, молекулярная динамика. 


\section{Introduction}

Nanocrystalline metals have a wide range of unique physical and mechanical properties, in particular, ultrahigh strength and hardness, increased wear resistance due to nanoscale and interface effects [1-3]. High demand for nanostructured materials in various practical applications stimulates the active study of the role of their internal structure, in particular, the grain boundaries (GB) in the features of plasticity nucleation and development under mechanical loading $[4,5]$. However, the small grain size creates significant difficulties for the study of important details of the deformation behavior of such materials at the atomic level within the framework of experimental approaches. Due to the rapid progress of computer technologies, simulation is becoming an increasingly powerful and effective tool for studying, analyzing and predicting various fundamental static and dynamic properties of nanocrystalline materials.

The most accurate simulation method for studying the properties of materials at the atomic level is based on the firstprinciples approach. However, the size of the system under study in this case is limited by several thousand atoms. An alternative to this approach is molecular dynamics simulation based on a semi-empirical interatomic potential, which allows studying systems containing up to several billions of atoms [6]. The widespread use of molecular dynamics simulation has led to a significantly deeper understanding of the deformation mechanisms of metal materials $[3,7]$. This progress has been also considerably promoted by the improvement of visualization tools [8] and methods for identifying various structural defects $[9,10]$ used in analyzing structural changes on the atomic scale.

Molecular dynamics simulation of the mechanical response and deformation mechanisms of nanocrystalline $\mathrm{Al}$ under uniaxial tension was carried out in [11]. The authors studied in detail the deformation mechanisms induced by grain boundaries in nanocrystalline Al. It was shown that the role of those mechanisms increased significantly as the grain size decreased to the nanometer scale. In this case, the usual dislocation deformation mechanisms are gradually replaced by the GB-induced mechanisms [12].

Note that shear stresses are realized in materials at almost any mechanical loading. The shear-coupled GB motion is an important mechanism for the plasticity of nanocrystalline metals. Simulation of the behavior of the $\Sigma 9[110](221)$ and $\sum 17$ [110](223) symmetric tilt GBs in iron crystallite under shear loading is carried out using the molecular dynamics method in [13]. The authors investigated the effect of temperature and strain rate on the shear-coupled GB motion. They calculated the coupling factor (the ratio of the GB translation velocity to the GB migration velocity) and built the dependence of that factor on the misorientation angle for the [110] symmetric tilt GB of bcc metals. Several geometric models of the coupling factor for metals with an fcc lattice were proposed in [3]. The model had two modes that corresponded to the ideal Burgers vectors of dislocations in bcc metals. The values of the coupling factor for one of the modes are in good agreement with the results of molecular dynamics simulation for both investigated GBs.

Shear loading can lead to high-speed migration of GBs in nanocrystalline materials [14]. Depending on the angle of misorientation of the grains and the shear rate, the speed of GB migration can vary in a wide range and reach several hundred meters per second. Although high values of stresses can be achieved during the shear loading process, high-rate displacement of GBs occurs without nucleation of structural defects.

This paper is devoted to the study of the behavior of a symmetric tilt GB in nanocrystalline nickel under highrate shear loading. The choice of nickel as an object of study is due to the widespread use of nickel alloys in various practical applications and the presence of reliable interatomic interaction potentials for this metal.

\section{Methods and setup}

As in [15-17], the software package LAMMPS [18] based on the molecular dynamics method was used for simulations. The interatomic interactions in $\mathrm{Ni}$ were described on the basis of the embedded atom method potential [19]. The simulated sample had the shape of a parallelepiped and contained about 70000 atoms (Fig. 1). The size of the simulated sample was $\sim 110 \times 110 \times 60 \AA$ A. Periodic boundary conditions were set in the $X$ and $Z$ directions. Regions with a thickness of $15 \AA$ from each surface in the $Y$ direction were declared grips (colored yellow in Fig. 1a). The grips were displaced as a whole in opposite directions along the $X$ axis with a velocity of $5 \mathrm{~m} / \mathrm{s}$. The initial temperature of the sample was $300 \mathrm{~K}$. Simulations were carried out for crystallites containing the $\Sigma 5(310)[001]$ symmetric tilt grain boundary. The gammasurface minimization algorithm [20] was used to construct GBs. The results of simulations were visualized with graphical package OVITO [8]. The volume per atom in the simulated sample was called atomic volume. To find it, a Voronoi polyhedron was constructed for each atom and its volume was calculated.

\section{Simulation results}

\subsection{GBs migration}

The results of the calculations showed that the application of shear loading led to high-speed migration of GBs (Fig. 1). To analyze the features of the GB migration in the crystallite, a vertical layer was selected. It is colored yellow in Fig. 1. It can be seen that the atoms of the region located between the initial and final positions of the GB (Fig. 1b) have a pronounced gradient of displacements. At the same time, the atoms of the regions located above and below the initial and final positions of the GB are displaced along with their grips at equal distances. This behavior of grain boundaries, called the shear-coupled grain boundary motion, was found experimentally [21] and plays an important role in the growth of grains and recrystallization processes. To characterize this GB motion, the coupling factor is used, the definition of which is given in the introduction. It can also be defined as the ratio of the amount of the lateral displacement of the grains $(S)$ to their normal displacement $(H)$ (see Fig. 1b):

$$
b=S / H .
$$



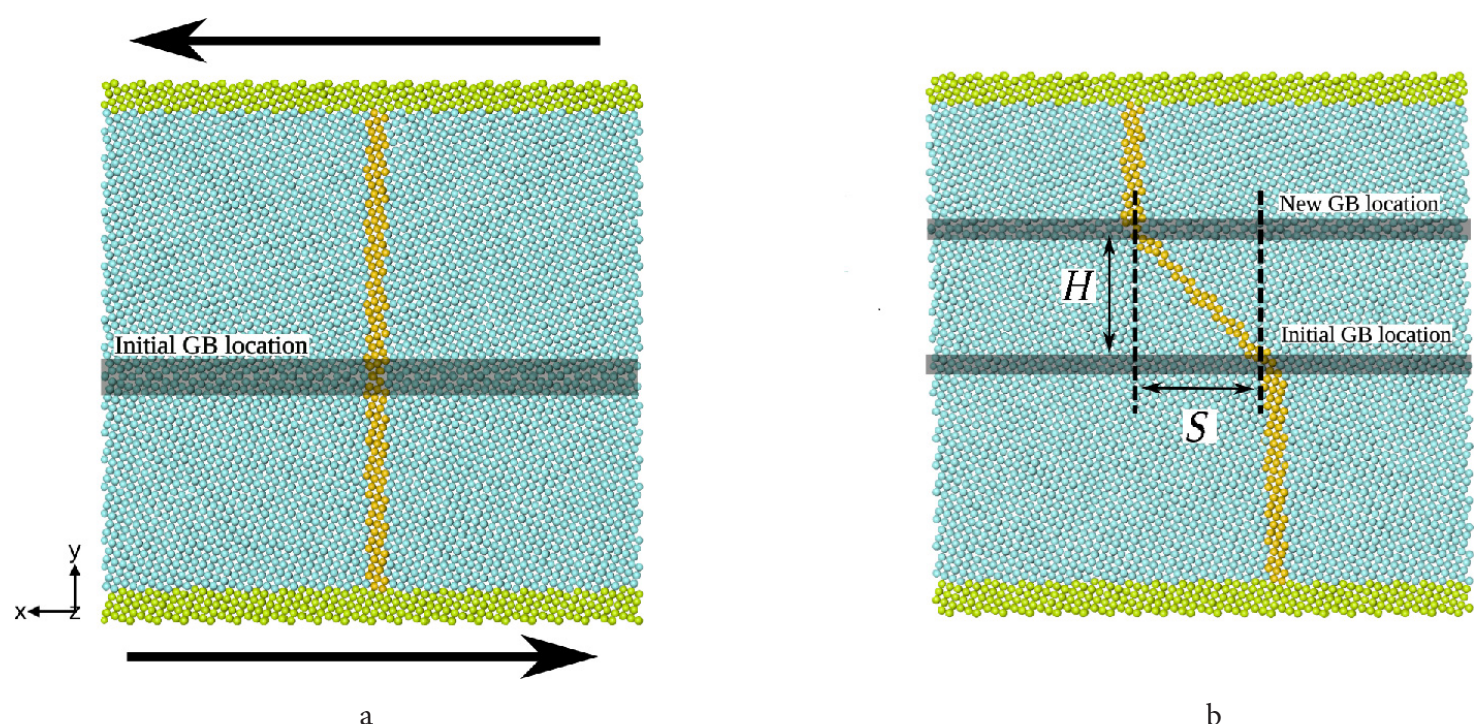

b

Fig. 1. (Color online) The structure of the crystallite and the position of the GB at different instants of time after the start of the loading: 0 ps (a); after $300 \mathrm{ps}$ (b). The arrows in the figure (a) show the direction of the grip motion. The orange line in the figure (b) shows the position of the atoms, which formed a vertical straight line along the center of the sample before loading.

The magnitude of the coupling factor depends primarily on the structure of the GB and can vary with the crystallite temperature for some GBs [13]. It is approximately equal to 1 for the GB considered in this paper.

Fig. 2 shows the dependence of the shear stress $\tau_{x y}$ and the position of the GB on time. It is clearly seen that the GB migration is intermittent and correlates well with the sawtooth-shaped behavior of the $\tau_{x y}$ curve. To activate the displacement, it is necessary to reach the threshold value of the shear stress. Thus, the pieces of growth on the stress curve correspond to the plateaus on the GB displacement curve. The drop pieces on the $\tau_{x y}$ curve correspond to the movement of the GB. The discreteness of the structure and the symmetry of the GB lead to a periodicity of changes in the curves in Fig. 2. At the same time, deviations from the periodicity are associated with thermal fluctuations of the atomic system of the simulated crystallite.

Analysis of structural rearrangements shows that there is a certain sequence of transformations of typical structural elements leading to the GB migration. Fig. 3 shows a fragment of the structure containing a GB region at different points in time. In the normal direction to the plane of the figure, the fragment consists of two (001) atomic planes. Atoms in the immediate vicinity of the GB, which initially belonged to the upper grain, are marked in color. Note that the blue and orange atoms belong to the same plane in the normal direction to the figure, while the green and pink atoms belong to the other plane. It was found that the colored atoms of the upper grain successively occupy three positions in the structure of the $\mathrm{GB}$, before adjusting to the structure of the lower grain (Fig. 3). The rearrangement of colored atoms from the upper grain to the structure of the GB, the successive occupation of three positions in the structure of the GB, and then the transformation to the structure of the lower grain are accompanied by four strong stress drops (Fig. 2) and the corresponding displacements in the $X Y$ plane, the values of which are given in the Table 1. The sequence of these four displacements provides the movement of the GB in the lateral and normal direction to

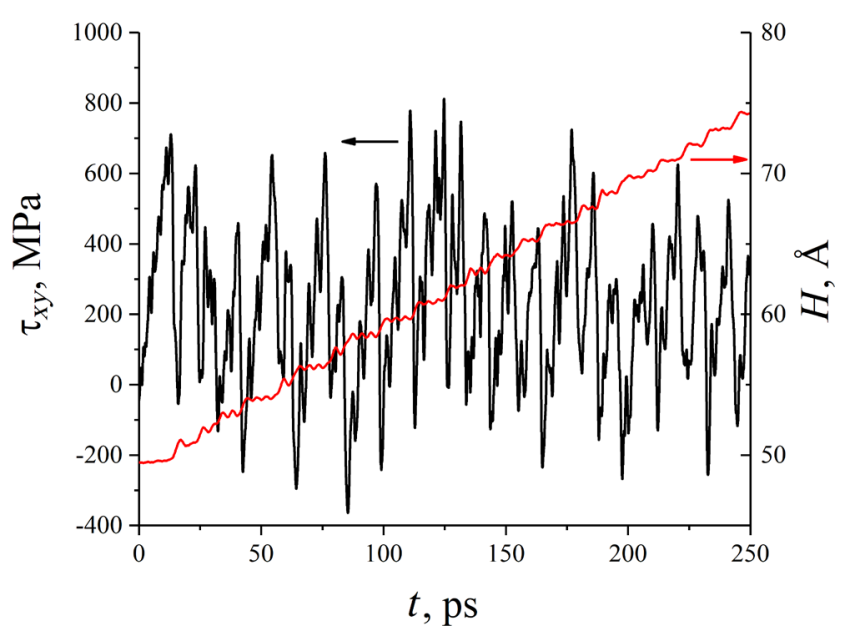

Fig. 2. (Color online) The dependence of the shear stress and the position of the GB on time.

its plane and the rearrangement of border atoms from the structure of one grain to the structure of another.

As can be seen from the above analysis, the migration of the $\sum 5(310)[001]$ symmetric tilt GB occurs without nucleation of any structural defects. The use of periodic boundary conditions prevents the rotations of the grains. Since the simulated tilt GB is symmetric, both of the crystallite grains will have the same shear moduli in the direction of the applied loading. Shear loading of a crystallite with such a structure does not lead to any volume driving forces. The displacement of GB is entirely due to the coupling effect.

\subsection{Atomic volume change}

It is known that the nucleation and development of plasticity in metals and alloys are accompanied by a local increase in the volume in the region of nucleation and at the front of the propagation of structural defects $[16,22]$. Structural transformations that determine the GB migration do not lead to the nucleation of structural defects, but the GB migration 


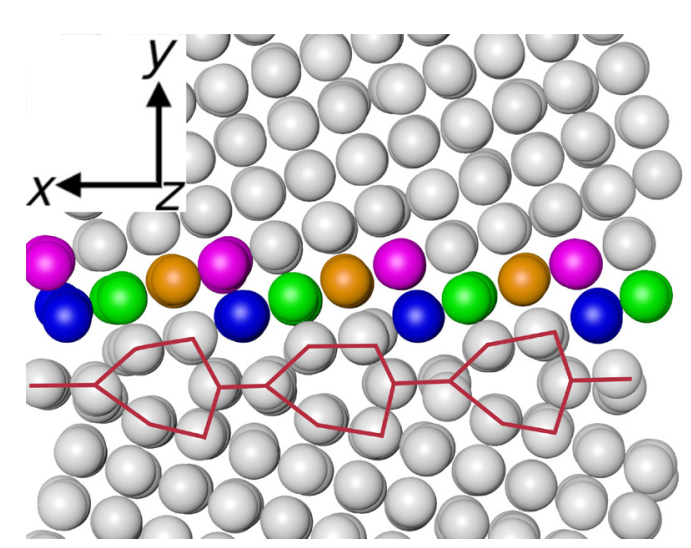

a

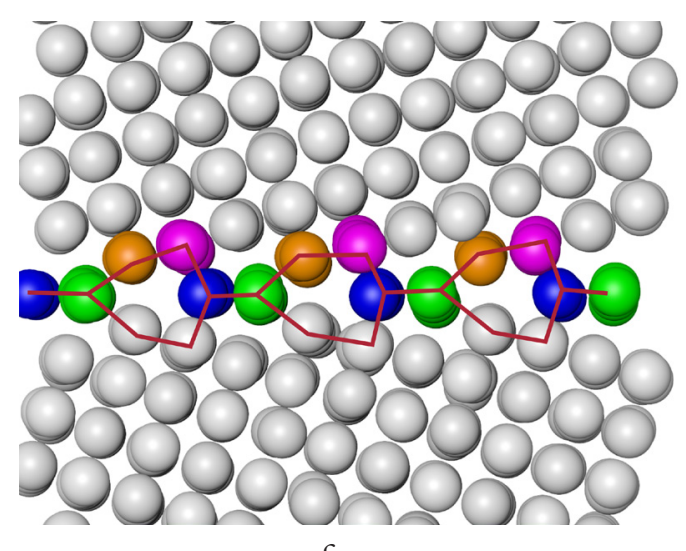

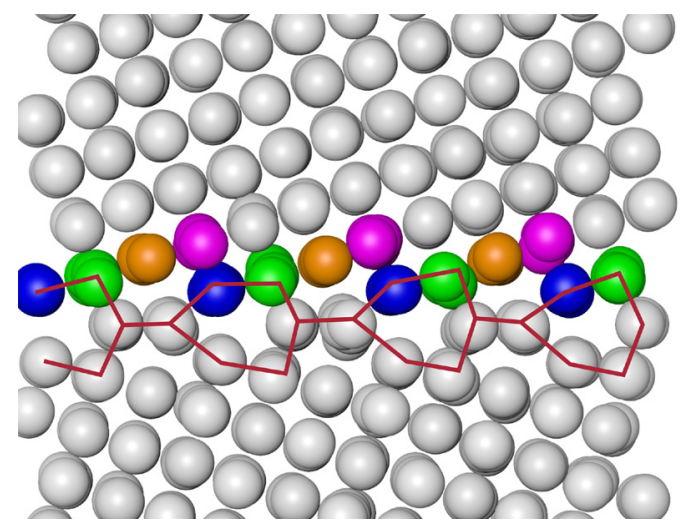

b

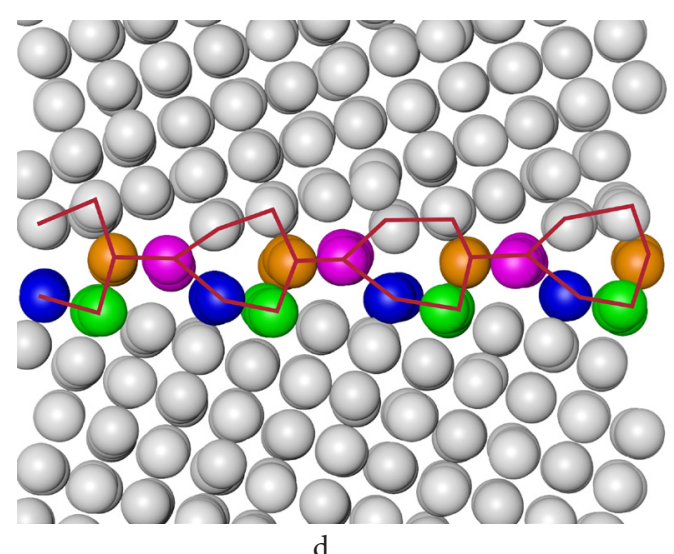

Fig. 3. (Color online)The fragment of the crystallite structure containing the GB at different instants of time after the start of the shear: 22.5 ps (a); 25 ps (b); 34 ps (c); 43 ps (d). Lines indicate the structural elements of the GB.

Table 1. Displacements of the colored atoms in Fig. 3 that provide the GB migration during shear loading.

\begin{tabular}{|c|c|c|c|c|}
\hline \multirow{2}{*}{} & \multicolumn{4}{|c|}{ Displacements, $\AA(X ; Y)$} \\
\cline { 2 - 5 } & 1 & 2 & 3 & 4 \\
\hline Blue atoms & $0.6 ; 0.0$ & $0.4 ; 0.1$ & $-0.5 ; 0.0$ & $-0.6 ; 0.1$ \\
\hline Green atoms & $0.6 ;-0.1$ & $0.4 ;-0.4$ & $-0.5 ;-0.5$ & $-0.6 ; 0.0$ \\
\hline Orange atoms & $0.6 ; 0.0$ & $0.5 ; 0.1$ & $0.5 ; 0.0$ & $-0.6 ; 0.1$ \\
\hline Pink atoms & $0.6 ; 0.0$ & $0.5 ;-0.1$ & $0.4 ;-0.4$ & $-0.5 ;-0.5$ \\
\hline
\end{tabular}

is the mechanism of the plastic deformation itself. One can expect that these transformations can also occur under conditions of significant deviations of the atomic volume. In the present work, we studied the features of volume change for those lattice atoms that are rearranged from the structure of one grain to the structure of another one during the GB migration. The atoms of two alternating planes along the $Z$ direction, through which the GB migrated, were selected to analyze the features of their volume changing. The calculation resultsforblue atomsin Fig. 3, belonging to one plane, and green atoms in Fig. 3, belonging to another plane, are shown in Fig. 4. Vertical lines in Fig. 4 correspond to the points of time for which the GB structure is shown in Fig. 3. It is seen from Fig. 4 that the values of the atomic volume corresponding to the vertical lines are in good agreement with the structures shown in Fig. 3. Thus, the characteristic values of the atomic volume are related to the specific positions of the selected atoms in the structural unit of the GB, which is marked by lines in Fig. 3. Green atoms, when the GB is passing through them, experience a significant jump in volume $(\sim 25 \%)$ compared with the initial value. Atoms of another plane, marked in blue, slightly reduce the atomic volume compared to the initial value when the GB is passing through them.

Note that the atomic volumes at 22.5 ps and 43 ps are characterized by slightly elevated values: $\sim 105 \%$ for blue atoms and $\sim 103 \%$ for green atoms (Fig. 4 ). In spite of the fact that the atoms at the indicated points of time belong to the grains, their proximity to the GB leads to an increase in their volume. 


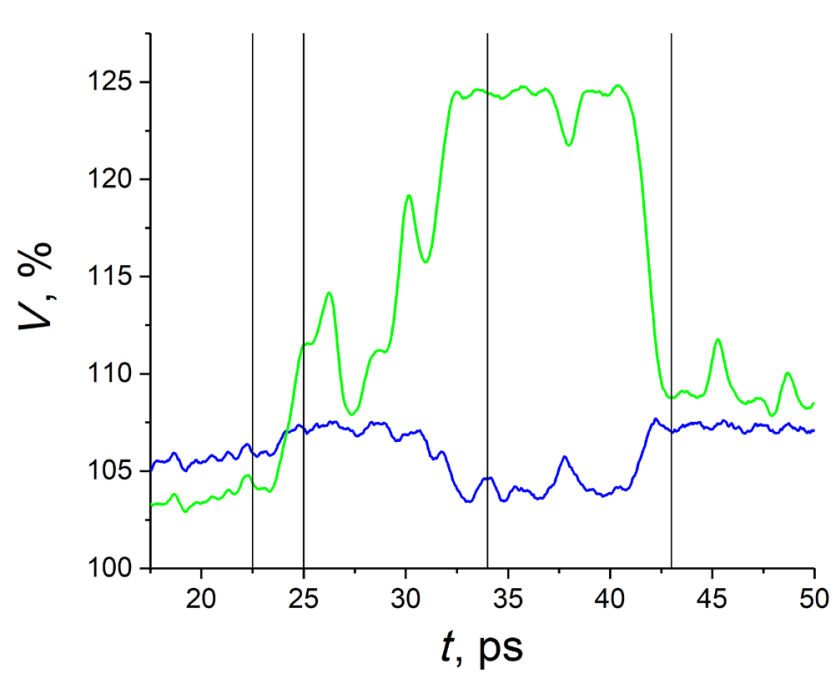

Fig. 4. (Color online) The change in the average atomic volume in different planes parallel to the GB over time.

\section{Conclusions}

The migration of a symmetric tilt grain boundary in Ni crystallite under shear loading was simulated using the molecular dynamics method. The sequence of structural transformations of the characteristic structural elements of the GB and the adjacent grain lattice, ensuring the migration of the GB, was determined. The GB movement had a jump-like nature. The shear stress curve as a function of time had a sawtooth shape. The GB experienced lateral and normal displacement when the applied shear stresses reached their maximum value and began to decrease rapidly. It was shown that the GB migration was accompanied by a change in the volume of atoms which belong to the planes involved in structural rearrangements.

Acknowledgements. Studies in Section 3.1 were performed under the Fundamental Research Program of the State Academies of Sciences for 2013 - 2020 (line of research III.23). Studies in Section 3.2 were carried out with the financial support of the Russian Science Foundation (project No. 17-19-01374).

\section{References}

1. I. Ovid'ko, R. Valiev, Y. Zhu. Prog. Mater Sci. 94, 462 (2018). Crossref

2. E.N. Hahn, M.A. Meyers. Materials Science and Engineering: A. 646, 101 (2015). Crossref

3. Y.Mishin, M. Asta, J. Li. Acta Mater. 58, 1117 (2010). Crossref

4. D. Wolf, V. Yamakov, S. Phillpot, A. Mukherjee, H. Gleiter. Acta Mater. 53, 1 (2005). Crossref

5. M. Dao, L. Lu, R. Asaro, J. D. Hosson, E. Ma. Acta Mater. 55, 4041 (2007). $\underline{\text { Crossref }}$

6. Y. Shibuta, S. Sakane, E. Miyoshi, S. Okita, T. Takaki, M. Ohno. Nat. Commun. 8, 10 (2017). Crossref

7. L. Zhang, C. Lu, K. Tieu. Comput. Mater. Sci. 118, 180 (2016). Crossref

8. A. Stukowski. Modell. Simul. Mater. Sci. Eng. 18, 015012 (2010). Crossref

9. A. Stukowski. Modell. Simul. Mater. Sci. Eng. 20, 045021 (2012). Crossref

10. A. Stukowski, K. Albe. Modell. Simul. Mater. Sci. Eng. 18, 025016 (2010). $\underline{\text { Crossref }}$

11. L. Zhang, Y. Shibuta, X. Huang, C. Lu, M. Liu. Comput. Mater. Sci. 156, 421 (2019). Crossref

12. V. Yamakov, D. Wolf, S. R. Phillpot, A. K. Mukherjee, H. Gleiter. Nat. Mater. 3, 43 (2003). Crossref

13. J. Yin, Y. Wang, X. Yan, H. Hou, J.T. Wang. Comput. Mater. Sci. 148, 141 (2018). Crossref

14. D.S. Kryzhevich, K.P. Zolnikov, A.V. Korchuganov. Comput. Mater. Sci. 153, 445 (2018). Crossref

15. K.P. Zolnikov, A. V. Korchuganov, D.S. Kryzhevich. Comput. Mater. Sci. 155, 312 (2018). $\underline{\text { Crossref }}$

16. A. V. Korchuganov, A.N. Tyumentsev, K.P. Zolnikov, I.Y. Litovchenko, D.S. Kryzhevich, E. Gutmanas, S. Li, Z. Wang, S. G. Psakhie. J. Mater. Sci. Technol. 35, 201 (2019). Crossref

17. K. Zolnikov, A. Korchuganov, D. Kryzhevich. Phys. Mesomech. 21, 492 (2018). Crossref

18. S. Plimpton. J. Comput. Phys. 117, 1 (1995). Crossref

19. S. M. Foiles, M. I. Baskes, M. S. Daw. Phys. Rev. B. 33, 7983 (1986). Crossref

20. Y. Mishin, D. Farkas. Philos. Mag. A. 78, 29 (1998). Crossref

21. T. J. Rupert, D.S. Gianola, Y. Gan, K. J. Hemker. Science. 326, 1686 (2009). Crossref

22. S. Psakhie, K. Zolnikov, D. Kryzhevich. Phys. Lett. A. 367, 250 (2007). Crossref 